\title{
TOWARDS ECO-NEIGHBORHOODS, SOLUTIONS FOR SUSTAINABLE DEVELOPMENT, CONSTRUCTION AND ENERGY SAVING TECHNOLOGIES
}

\author{
Osama OMAR ${ }^{\star}$ \\ Faculty of Architecture, Design and Built Environment, Beirut Arab University, Beirut, Lebanon
}

Received 07 February 2017; accepted 30 August 2017

\begin{abstract}
Global interest in the concept of sustainability has prompted the swift and extensive developments of green technologies, products, competitions, organizations, and resources. As evidenced by international environmental agreements and conferences held that aim to resolve global warming such as the 2009 UN Climate Change Conference in Copenhagen, the world is becoming focused on sustainable policies and practices. This research will address the urban problems in present in Arab countries including environmental pollution and the evident social problems like disintegration and isolation by studying the three zones of Mar Mikhael, Arab el-Maslakh, and Nour Hajin which are known to be economically unequal. The methodology of this research is based on the analytical study of the three interdependent components of sustainable development and design which are society/people, the environment, and economics applying on each case study. This paper will identify solutions relative to environmental, technological, energy saving, as well as sustainable and green buildings in urban design. Some of the remaining solutions target solving environmental pollution and social problems. Others target to improve the quality of the economic level of the neighborhood. The result of this research will a number of recommendations on several levels (Governmental level, Local NGOs). Another type of results will be as architectural design solution for environmental issue and urban problems based on data collection of case study at several items by team of students attending in local competition of urban design.
\end{abstract}

Keywords: Eco-neighbourhoods, energy saving, sustainable developments, urban design, green buildings.

\section{Introduction}

Mdawar district is situated in the northeast of the capital Beirut (see Figure 1) and is considered a gateway for comers from northern Lebanon. Being adjacent to the Port of Beirut, this neighborhood's function is affected by its location which is reflected in the services that have histori-

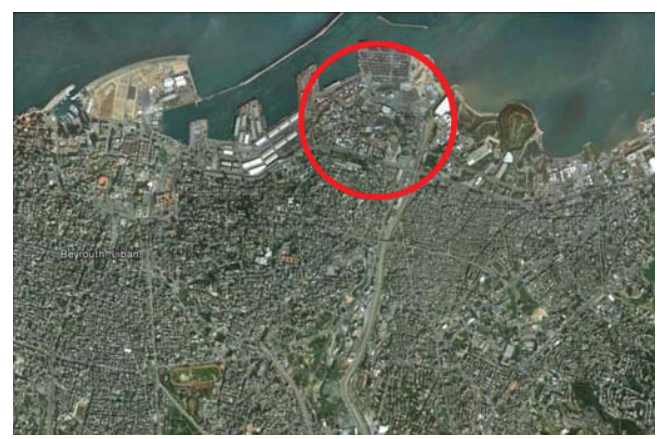

Figure 1. The location of Mdawar District in Beirut cally been established in the region (see Figure 2) (Beirut Municipality \& Build it Green Lebanon, 2016).

In the last decade, Mdawar established the services that were undesirable in the heart of the Capital. Additionally, the project of expanding the port of Beirut has bridled the possibility of the neighborhood's development. Several restrictions halted the development in the district

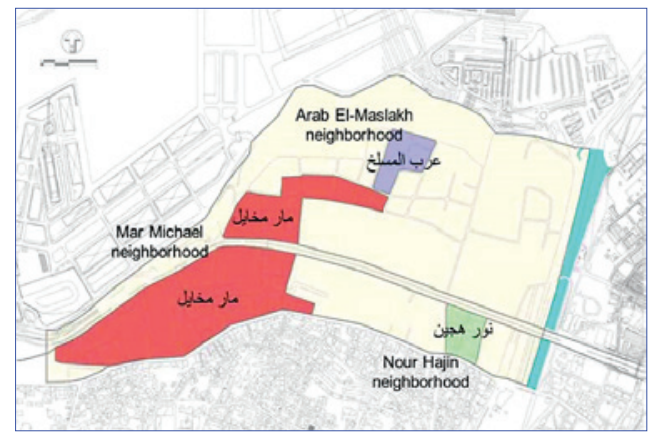

Figure 2. Specified locations to be studied in order to resolve the Social fragmentation in Mdawar District

*Corresponding author. E-mail: o.omar@bau.edu.lb; ossamamoh.omar@gmail.com 
resulting in the abundance of empty plots or plots with temporary installations. During the last five years, this became more evident, which led to the attraction of building construction works to the outskirts of Mdawar. The threat of an unorganized construction boom in the area which can play an active role in the economic dynamics of the city, has encouraged the Municipality of Beirut to consider an urban project that could ensure a promising future to the neighborhood (Beirut Municipality \& Build it Green Lebanon, 2016).

With this in mind, this problem was assigned to third level students in 'City and Town Planning' Course in Faculty of Architecture, Design and Built Environment, which required the preparation of a comprehensive study of the neighborhood and led to the formation of a strategic plan with a proposed vision for the Mdawar neighborhood.

\section{Main problems}

From the study, it is clear that the main problem in the Mdawar district is related to social, economic, and environmental issues, which will be explained further below.

\subsection{Current situation}

Mdawar is composed of three social blocks; each one of them is situated in a specific area in this district and has its own particular characteristics (see Figure 2).

\section{- The Nour Hajin neighborhood}

This area, located in the eastern section of the district, has population mostly of Armenian origin. The Beirut River separates it from Bourj Hammoud on its eastern side and from the west, it is bordered by the railways station of Mar Michael. Charles Helou Avenue, being the main vital artery that connects the North to Beirut, borders Mdawar on the North. The neighborhood includes a church, a legacy for the local Armenians, in which they meet on several occasions (Beirut Municipality \& Build it Green Lebanon, 2016).

\section{- The Arab el-Maslakh neighborhood}

It is located in the northern part of the district and is bounded from the northern side by the port of Beirut, from the east by several industrial facilities, and from the south by municipal lands and facilities. It is considered as a lower social class residential area (Beirut Municipality \& Build it Green Lebanon, 2016).

- The Mar Michael neighborhood

It is located in the southwest of Mdawar, near the Port of Beirut and is divided into two parts due to the crossing of the Charles Hélou Avenue. It is bordered to the east by the railway station, and separated from the Arab el-Maslakh neighborhood by the municipal garden. From the southern and western sides, it is bounded by the residential areas of Saifi, Gemmayze, and Rmeil. This neighborhood is known to be populated mainly by Maronites and it took its name from the Mar Michael church located in it (Beirut Municipality \& Build it Green Lebanon, 2016).

\subsection{Social situation (disintegration and isolation)}

Each neighborhood of the Mdawar is considered as a fragmented area with dislocated components each having its own qualities and behavioral particularities. It is affected by external factors such as the Port's dynamics and other economic activities. In addition to being economically unequal, social interactions are actually missing between the three groups of population highlighted above therefore increasing the rift among the local population groups, and depriving the Mdawar district of a clear identity, thus hindering its rich demographic and cultural diversity (Beirut Municipality \& Build it Green Lebanon, 2016).

Although the district has plenty of empty plots with diverse functions, it only has a few communal places where inhabitants can actually meet. The public garden located in the northern part is the only green space, but it lacks the required facilities that encourage families to meet together therefore inducing social fragmentation. Meanwhile, places for leisure are available in the southern part, and somehow fit with the social and financial conditions of the population within this neighborhood (Beirut Municipality \& Build it Green Lebanon, 2016).

Historically, the district attracted labor in conformity with the functional nature of the area. However, with the emergence of technological development, unemployment increased as the need for manual labor declined. Since then, the social situation worsened and the district immersed in poverty. This resulted in the constitution of a young marginalized social class with no ability to create a social change (Beirut Municipality \& Build it Green Lebanon, 2016).

\subsection{The morphology of Mdawar, a non-traditional blend}

The third-sector nature of the district is dominant since its constitution. The railways station and the extension of the Port, as well as the appearance of skyscrapers emerging in the south and the accumulation of heterogeneous equipment in the neighborhoods, have had a significant impact in determining the shapes and sizes of buildings surrounding these facilities. This lead to associating the district landscape with a negative stereotype (see Figure 3).

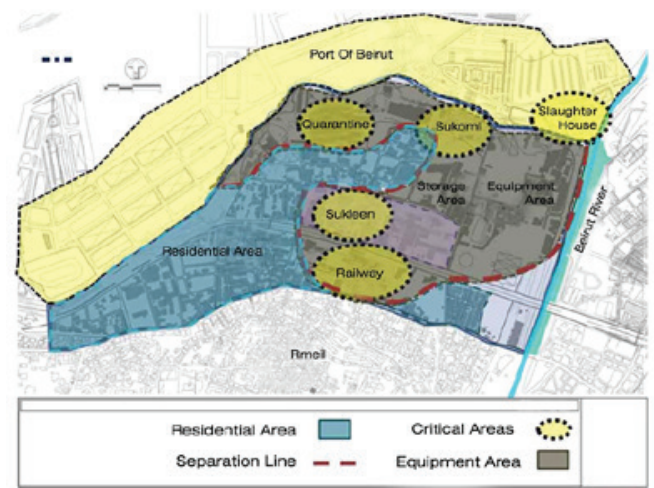

Figure 3. The impact of historical events on the constitution of the Mdawar District 


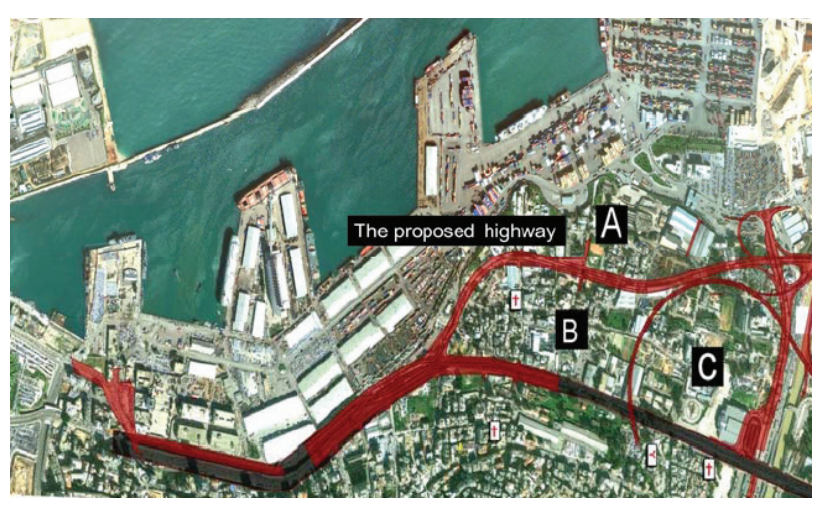

Figure 4. The impact of the new proposed highway and railways

The high density in the neighborhoods of Arab el-Maslakh and Nour Hajin should be highlighted in comparison with the other areas of Mdawar (Beirut Municipality \& Build it Green Lebanon, 2016).

It is highly likely that the division that occurred in Mdawar, in particular at a social and morphological level, will be repeated in the future with the implementation of the new highway which is part of the Linor project. This highway will cause a new rupture, cutting the district into three separate physical zones and increasing the problem at the social level (see Figure 4) (Beirut Municipality \& Build it Green Lebanon, 2016).

On the Real Estate front, Mdawar has a great variety in terms of properties and construction, which could be the basis of the district's future growth. Today however, these capabilities are either untapped, exploited ineffectively, or constrained by some authorities. Many smaller plots in the areas of Nour Hajin and Arab el-Maslakh are not tagged by any development projects as a result of being subject to inappropriate regulations which in in many cases where associated with the expansion of the port. Fortunately, these restrictions have been recently removed and the urban development of the district is thus possible again (Beirut Municipality \& Build it Green Lebanon, 2016).

\subsection{The attracted economic situation between inside and outside}

Mdawar has an important geographical location in the capital Beirut characterized by easy accessibility, as it is located along the main entrance to Beirut and is close to the Beirut Central District. This feature is considered an attractive factor at the social and economic levels. Thus, the economic structure is influenced by internal and external factors, and is based on multiple sources and exchanges (Beirut Municipality \& Build it Green Lebanon, 2016).

The economic mechanisms of Mdawar are varied comprising of institutions for storage in the north, Art Galleries and offices in Mar Mikhael, and a variety of craftsmanship in the Arab El-Maslakh area and in Nour
Hajin therefore influencing unharmonious development of economic infrastructures. The lack of concern for the capacities development of national facilities decreases the expected performance quality resulting in the attraction of a cheap non-specialized labor to Mdawar to work in Sukleen, the factories, and the port. The recovery of nearby shops and the increase in the demand for low-income rental housing was the outcome (Beirut Municipality \& Build it Green Lebanon, 2016).

On the other hand, the presence of the Forum de Beyrouth and the spread of nightclubs in the southern and eastern sections aided in forming a new economic facade based on nightlife activities. The Port of Beirut, located on the northern side on the waterfront of the district, is considered to be a fundamental economic force with an impact at a national level. It contributes in providing employment opportunities and an increased demand for rental housing. The presence of this Port requires an easy access in and out of the neighborhood through main roads (Beirut Municipality \& Build it Green Lebanon, 2016).

The existence of multi-service facilities in Mdawar, led to the development of a critical environmental situation in the region due to several negative factors. In addition to major traffic jams, the cargo transit in the area has a large environmental burden, both being reflected in the significant air and sound pollution. Subsequently, this encouraged residents, whose economic conditions were adequate to leave the district to other areas where better services and a cleaner and healthier environment existed. In addition, the local infrastructure suffers from several problems causing odor pollution and urgently needs to be developed. (Sewage and storm water drainage) We should also note here the disparity between the northern and southern parts of Mdawar with regards to the implementation of infrastructure projects (Beirut Municipality \& Build it Green Lebanon, 2016).

\section{Main objective}

- Environmental objective: Nulling emissions of greenhouse gases as well as resolving practices that emit them by halting the usage of renewable resources.

- Economic objective: Take part in the actions concerning the economic dynamics of the city, considering that the Municipality of Beirut plans to launch urban project that could provide the neighborhood with a healthier future.

- Culture and Social objective: Knowing that Mdawar district, being a fragmented area with dislocated components having their own qualities and behavioral particularities, is affected by external factors such as the Port's dynamics and other economic activities, forming rift among the local population groups, it is necessary to close the gap and give the Mdawar district a clear identity, thus presenting its rich demographic and cultural diversity. 


\section{Methodology}

The study consists of several phases:

- In the First phase: Surveying Work Maps including Base Map, Satellite Map, Zone \& Boundary Map, Land Use Map, Heights Map, Physical Conditions Map, Building Age Map, Road Network Map, Architecture Style Map (Moughtin, Cuesta, Sarris, \& Signoretta, 2003).

- In the second phase: Forming a diagnosis that includes a sectorial and transversal analysis of the different issues, a SWOT analysis that leads to highlighting the stakes involved (Strength and Opportunity for Mdawar District, Weakness and Threats for Mdawar District), and a Service Map for Mdawar District, on which the strategic plan will be based (Moughtin, Cuesta, Sarris, \& Signoretta, 2003).

- In the third phase: Final Proposal for Solutions (In this phases each group should submit advanced solutions for sustainable development and construction based on all of the above main parameters and criteria, incorporating proved construction). A reference plan must be elaborated with all the actions that were identified to be implemented in Mdawar (Moughtin, Cuesta, Sarris, \& Signoretta, 2003).

\section{Sustainable development for Eco- neighborhoods}

At the brink of the 21st century, studies showed that nearly half of the world's population were living in towns and cities. Over the time of the coming decades, urban population growth and economic development in emerging countries is expected to grow exponentially.

Knowing that by $2050,70 \%$ of the world's people will be urban dwellers, the main challenge for cities will become controlling consumption and pollution while maintaining efficiency. Cities are known to be a foremost source of resource consumption, environmental impacts and social challenges. They justify for $60 \%$ of the planet's water usage, $70 \%$ of its consumption of energy resources, and are responsible for more than $75 \%$ of greenhouse gas emissions.
Yet urbanization cannot be considered a completely negative phenomenon because it is the motivation to promote more sustainable development (Veolia Group, 2017).

\subsection{Principles and theories}

In 1987, the World Commission on Environment and Development report (also known as the Brundtland Report) provided an authoritative definition of the definition of sustainable development. Accordingly, "Humanity has the ability to make development sustainable - to ensure that it meets the needs of the present without compromising the ability of future generations to meet their own needs. Sustainable development is not a fixed state of harmony, but rather a process of change in which the exploitation of resources, the direction of investments, the orientation of technological development, and institutional change are made consistent with future as well as present needs" (Brundtland, 1987).

This definition of sustainable development emphasizes two crucial points. Not only does it accept the concept of 'needs', in particular those basic needs for human life, but also the 'needs' to allow a comfortable way of life. Second, it admits the concept of 'making consistent demands' on technology and social organizations in response to the environment's ability to meet present and future needs. This reaches local and global concerns and has a political dimension, embracing issues of resource control and the inequities that exist between developed and developing nations (Williamson, Radford, \& Bennetts, 2003). Also, Sustainable Design can define as a method of designing and constructing a building that minimizes burdens on natural resources and environment (see Figure 5).

In Other Hand, Sustainable Design has three main approaches: environmental, social, economic. The environmental approach is divided in to Five Principles:

1. Sustainable Site Planning.

2. Safeguarding Water and Water Efficiency.

3. Energy Efficiency and Renewable Energy.

4. Conservation of Material and Resources.

5. Indoor Environmental Quality (Atkinson, Dietz, \& Neumayer, 2007).
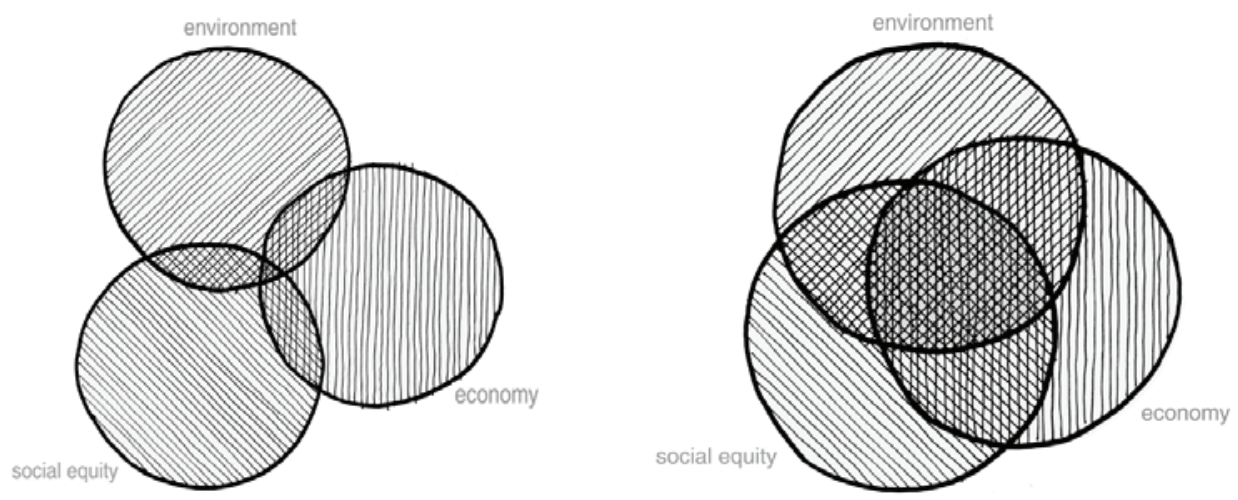

Figure 5. Overlapping spheres of economic, environmental and social sustainability. In the figure on the left, the action represented by the darkest area does not show significant consideration of all spheres. In the figure on the right, the action taken has met the needs of much of each sphere, representing a more sustainable choice (Sands, 2013) 
UN-Habitat aids countries in developing urban planning methods and systems to respond to current urbanization challenges such as population growth. The landscape of these cities has changed considerably because of rapid urban population growth. A main character of fast spreading cities is urban sprawl, which grubs large areas of land and is usually accompanied by many serious problems. In addition to land use conjecture, formation of fragmented and inefficient urban space where urban advantage and city concept are missing became the current status of city growth. Future cities are meant to build different types of urban structure and space, where city life thrives and the most common problems of current urbanization are resolved. UN-Habitat proposes an approach that summarizes and refines existing sustainable urban planning theories to help build a new and sustainable relationship between urban dwellers and urban space, and to increase the value of urban land. This approach is based on 5 principles that support the 3 key features of sustainable neighborhoods and cities: compact, integrated, connected.

The Five Principles are:

1. Adequate space for streets and an efficient street network. The street network should occupy at least 30 per cent of the land and at least $18 \mathrm{~km}$ of street length per $\mathrm{km}^{2}$.

2. High density. At least 15.000 people per $\mathrm{km}^{2}$, that is 150 people/ha or 61 people/acre.

3. Mixed land-use. At least 40 per cent of floor space should be allocated for economic use in any neighborhood.

4. Social mix. The availability of houses in different price ranges and tenures in any given neighborhood to accommodate different incomes; 20 to 50 per cent of the residential floor area should be for low cost housing; and each tenure type should be not more than 50 per cent of the total.

5. Limited land-use specialization. This is to limit single function blocks or neighborhoods; single function blocks should cover less than 10 per cent of any neighborhood (Unhabitat, n.d.).

Key features of sustainable neighborhoods:

The above principles indorsed by UN-Habitat are meant to take account for sustainable urban development by producing sustainable, livable and safe neighborhoods. This would require the following key features:

1. A vibrant street life: Promoting street life by empowering an assortment of activities, conducive frontage and street width, and reducing the presence and role of private transport. The Five Principles encourage mixed land use, which boosts street life noticeably. The already present high population density has a sufficient industrial and commercial service demand accompanied with mixed land use that provides required manufacturing and service space. Cities consistent with the Five Principles are able to link demand with supply and thus stimulate a prosperous city street life, which satisfies people's needs and creates a safe and vibrant city life.
2. Walkability: Promoting walkability is a crucial measure to bring people into public spaces, reduce congestion, and boost local economy and interactions. A healthy street life encourages people to circulate around, while providing necessary city administrative services to be offered within a secure radius. Walkability also contributes to reduce automobile dependency and thus alleviate congestion, air pollution and resource depletion issues.

3. Affordability: Promoting proximity and reducing costs and building services by maintaining affordability of transactions and economic activities is necessary. Proximity, indorsed by the Five Principles, helps to manage time and resources and thus brings down general service costs. Furthermore, the social mix principle encourages a rational distribution of urban public resources while providing adequate housing through city planning regulations so that to ensure social equity and promote proper economic activity.

\subsection{Energy saving technology and urban development}

Today, the world faces an unprecedented environmental crisis. We must being to reverse the damage inflicted on the planet since the Industrial Revolution. In 2002, the 2030 Challenge stated, "Scientists give us 10 years to be well on our way toward global greenhouse gas emissions reductions in order to avoid catastrophic climate change". Today, moving forward in a sustainable manner requires more than simply building new energy-efficient buildings or increasing the number of hybrid cars on roads. Making significant, demonstrable changes to our existing city landscape, altering not only how our city looks but how it works. An urban ecosystem relies on the true integration of each of a city's elements. Smart buildings rely on smart transit networks, smart energy system rely on the creation of smart infrastructure. The process of DeCarbonization aims to improve the performance of every major metropolitan system to create a healthier, more sustainable, more livable city (Smith \& Gill, 2011).

Sustainable Development Strategies (Eight Strategies):

1. Buildings: This strategy state of existing building stock, which consumes much more energy than necessary, due to the age and less efficient performance of the majority of current structures. Upgrading these buildings will both reduce carbon emissions and ensure future economic viability (Smith \& Gill, 2011).

2. Urban Matrix: This strategy should contain the analysis of real estate and land use and promote the creation of mixed-use which rate low carbon footprint. In addition by creating a vibrant urban core in the downtown area, including increased amenities, new schools, new parkway and schools to forces who work in the area to local resident (Smith \& Gill, 2011).

3. Smart Infrastructure: This strategy explores systems designed to optimize resource performance. It inspects 
regional trends in energy supply and distribution and focuses on low-carbon technologies, such as smart grids, which pursues adding city necessities through information technologies (Smith \& Gill, 2011).

4. Mobility: This strategy forms an assessment of transit and connectivity. Cities that have denser cores generally have lower per-capita gasoline consumption. Design solutions are proposed such as rail and bus commuting, bicycle and pedestrian routes and public service fleets, including taxis (Smith \& Gill, 2011).

5. Water: The purification, delivery and heating of potable water, as well as the treatment of wastewater, can reduce the overall carbon footprint of water in Beirut (Smith \& Gill, 2011).

6. Waste: Design solutions offer possibilities for reduce the carbon load of waste treatment (Smith \& Gill, 2011).

7. Community Engagement: Development of programs to engage citizens, like foundation of community action groups and education of younger citizens (Smith \& Gill, 2011).

8. Energy: An examination of existing and new energy sources like a wind farm or large-scale photovoltaic array, in addition of the replace greenhouse-gasemitting fossil fuel plants (Smith \& Gill, 2011).

\section{Analytical Study (Medawar District, Beirut, Lebanon)}

In this Analytical Study student of the course ARCH.338 "City and Town Planning", were divided into 7 groups, each comprised of 10 students. Each group was required to submit three phases of drawing to complete their Concept to transfer Mdawar district to Eco-neighborhood's.

5.1. First Phase: The target of the first phase is to build a clear understanding of the current situation of the Mdawar district including its components, history, and any past, recent, and future developments and plans. The aim is to provide needed information and inspiration to allow the students to build up and base their design on a real study.

This was ensured by working on collecting a package of Maps that contains Base Maps, Satellite Maps, Zone \& Boundary Maps, Land Use Maps, Heights Maps, Physi- cal Conditions Maps, Building Age Maps, Road Network Maps, and Architecture Style Maps (see Figure 6).

In order to control this phase, each group was given the task to work on updating the information and complete the maps mentioned above by conducting several site visits. The instructors supervised the first visits and then the students were allowed to collect the remaining data on their own as groups. Information about each building and their locations were upgraded to the Package of Maps. At the end of this phase, the outcome was presented on A1 boards and a group discussion was held to share the information and to ensure that the maps are compatible and complete. Then, the outcome was distributed to all groups to ensure that each member attained the information.

5.2. Second Phase: The target of this phase is to shed light on the strengths, weaknesses, opportunities, and threats of the district. In order to do so, each group was required to conduct a SWOT analysis that led to highlighting the stakes involved. Examples of SWOT analysis implementation were explained to the students before going through with the site analysis of this phase. As a method, several way of information collection lead to presentation methods that included pictures, videos of interviews with local people and of the area, and official informative reports and statistics (see Figure 7).

The main objective of this phase was to develop critical thinking amongst the students by clarifying the weaknesses and valuing the strength points of this area to provide a sturdy framework of this case study. This triggers the student's ability to form and propose applicable and effective solutions in their design.

5.3. Third Phase: Final Proposal for Solutions: In the third phase, the target was to form applicable and sustainable design solutions based on the previous research and analysis of phases one and two as well as several guidance lectures and group discussions done throughout the course. Each group of students proposed different efficient solutions and submitted them on multiple Al's and PowerPoint presentations that included regard to social, environmental, and economic principles. Some of the most common ideas in this phase included pedestrian bridges, rehabilitation of old historical buildings, public green areas,... etc. (see Figure 8).
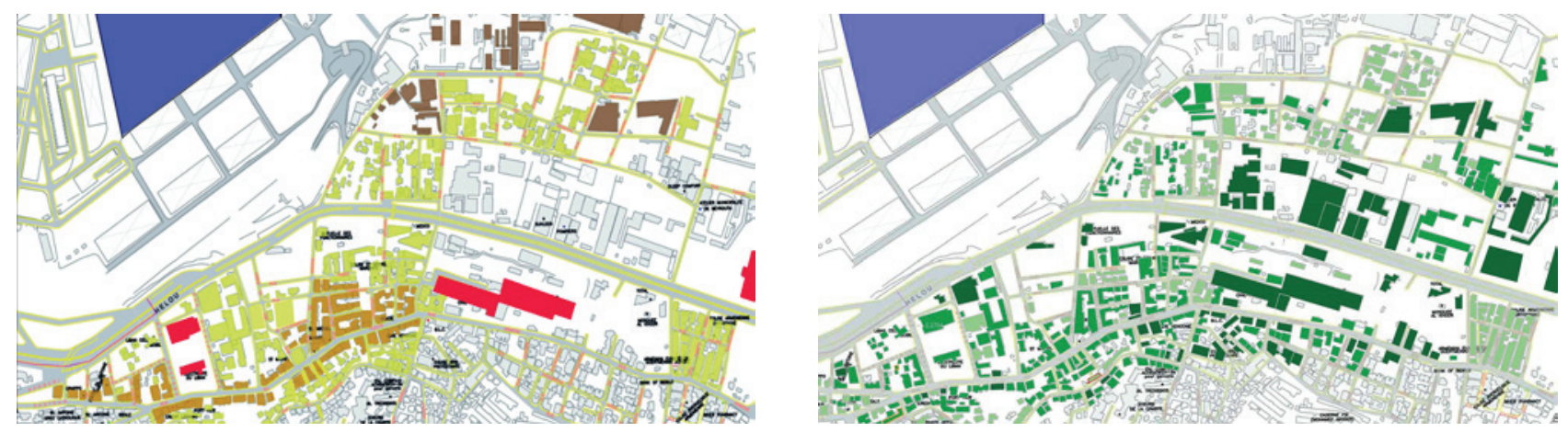

Figure 6. (Left Image) Land use map, (Right Image) Building age map 

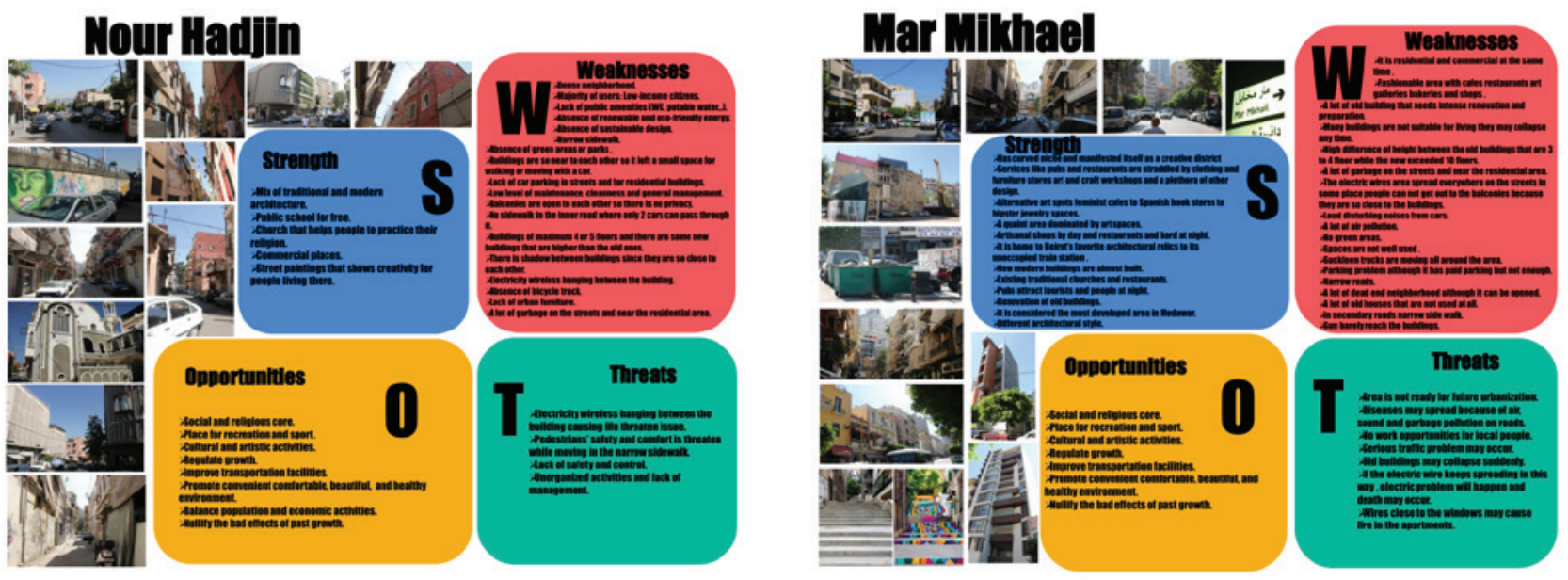

Figure 7. (Left Image) SWOT analysis for Nour Hadjin, (Right Image) SWOT analysis for Mar Mikhael
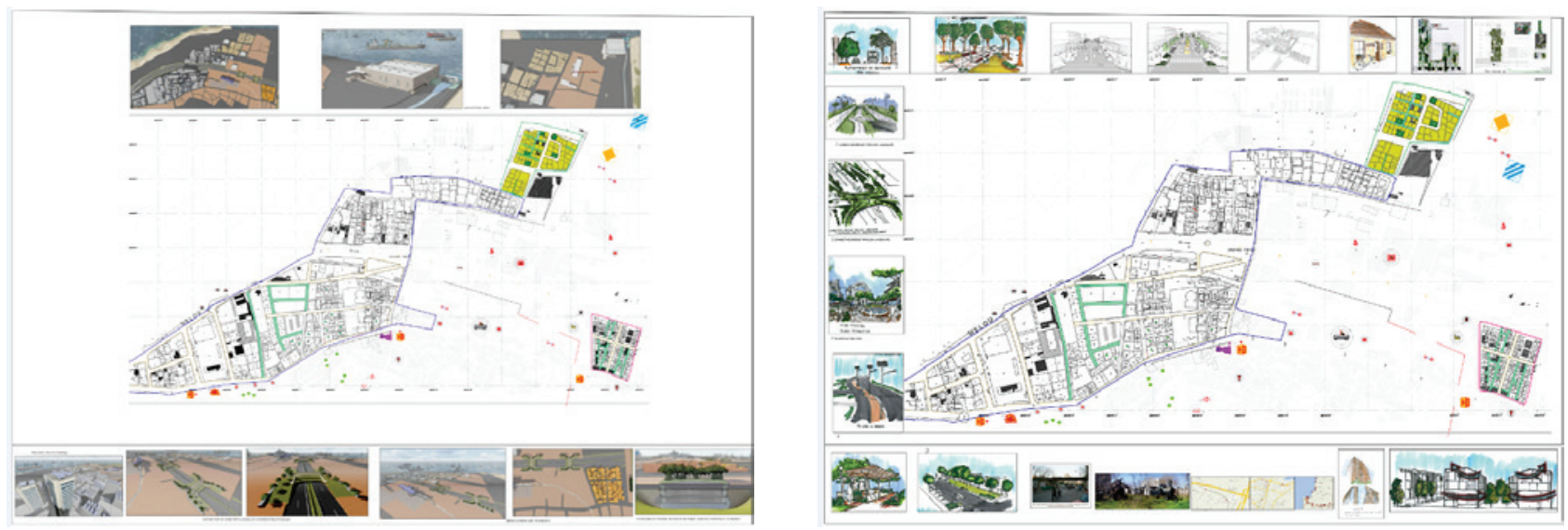

Figure 8. Final proposal for sustainable solutions

\section{Conclusions}

Finally, the proposed solutions to transfer Mdawar district to Eco-neighbourhoods dependent on low budget solutions and creative ideas as below:

- Increase green area and plants in urban fabrics by transfer some of empty plot to public garden to integrate green area between high densities to decreased greenhouse gasses emission and to create social places to communicate between three zones.

- Rehabilitation for old building with main change in using to adopt and meet neighbourhood needs with half mile.

- Make mixed used in building by make low part of building as commercial and middle part as resident to catch the gap between missing part in zone like (clinic unite, police office ...etc).

- Encourage investors by make facilities in port of Beirut, to transfer heavy industrial from Arab Al Maslakh to Port of Beirut.

- Transference Mar Mikhale zone to pedestrian area with little interaction with public transportation to encourage people to health life habits and decreased emission from private sector of transportation. Also, solve problem of traffic congestion.

- Encourage civil service associations to integrate with neighborhood residence to improve the quality of life for their children and them self.

- Launch community-based initiatives to preserve the environment with corroboration with governmental organization.

- Governmental organization should enactment the necessary rules to avoid unplanned building

\section{References}

Atkinson, G., Dietz, S., \& Neumayer, E. (2007). Handbook of sustainable development. Edward Elgar Publishing Limited.

Beirut Municipality \& Build it Green Lebanon. (2016, March). ECO-Quartier Conditions booklet for University Student Competition in Sustainable Design. In Proceedings of the Annual Build It Green - Lebanon Sustainability Solutions Conference. Beirut, Lebanon: Eco-Quartier.

Brundtland, G. H. (1987, March 20). Report of the world commission on environment and development: our common future. Oslo. 
Moughtin, C., Cuesta, R., Sarris, C., \& Signoretta, P. (2003). Urban design method and techniques (2nd ed.). UK: Architectural Press.

Sands, J. (2013). Sustainable library design. The U.S. Institute of Museum and Library Services.

Smith, A., \& Gill, G. (2011). Toward Zero Carbon: the Chicago Central Area DeCarbonization Plan. The images Publishing Group Pty.

Unhabitat. (n.d.). A new strategy of sustainable neighbourhood planning Five Principles. In Urban Planning Discussion Note 3. Unhabitat for a Better Urban Future.

Veolia Group. (2017). Sustainable cities. Retrieved from http:// www.veolia.com/en/veolia-group/profile/challenges/sustainable-cities

Williamson, T., Radford, A., \& Bennetts, H. (2003). Understanding sustainable architecture. Spon Press, Taylor and Francis group. 